\title{
BDA sets out 2019 manifesto for oral health
}

On 15 November the British Dental Association (BDA) called on all parties to stop treating oral health as the missing piece in health policy, as it launched its 2019 manifesto (pictured).

Setting out its key priorities for the next parliament, the Association has built on work that has secured a Health Committee Enquiry into NHS dentistry, forced government to change tack on fines, and helped secure extension of the Practitioner Health Programme to dentists.

In a call for a joined-up approach, the BDA has backed parallel action around three core priorities:

- A valued workforce. Provide support to attract and retain talent. Make NHS dentists part of the NHS family, through tried-andtested initiatives that recognise and reward commitment

- Remove barriers to care. Tackle the obstacles standing in the way of patient care, through a long-term funding settlement for NHS dentistry

- Put prevention first. Invest to save, by tackling inequalities, and focusing on prevention - not just cure.

The BDA is already actively engaging with the major parties and is leading with calls for support and workforce initiatives extended to other health professions to be applied consistently to dentists.

The latest BDA survey indicates half of dentists (50.3\%) are actively considering reducing NHS hours to avoid exposure to pensions tax charges, and the BDA is pressing for the profession to be extended the same

flexibilities offered to medics.

In a bid to stem the

ongoing recruitment and

retention crisis the BDA has said lessons must also be learned from successes such as the GP Targeted Enhanced Recruitment Scheme, alongside the restoration of commitment payments. Currently the lowest levels of morale are among practitioners with the highest

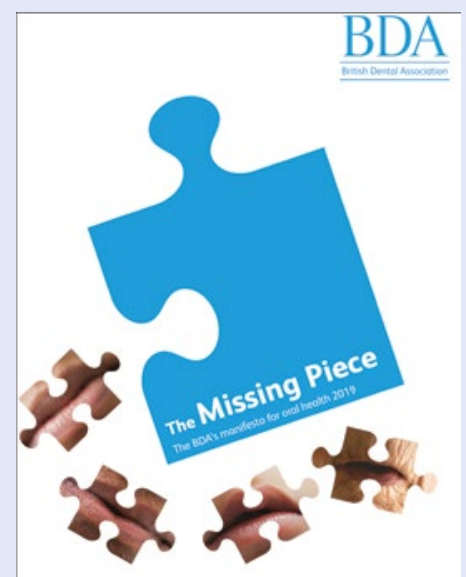
NHS commitment.

Dentist leaders have called time on the decade-long freeze on the dental budget, an end to inflation busting charge increases, and extension and simplification of NHS charge exemptions.

Funding has failed to keep pace with both population growth and inflation, with the service in England operating on a lower budget in cash terms - than it received in 2010/11 (then $£ 2.814$ billion).

BDA Chair Mick Armstrong said: '[This document] reflects our belief that real progress will require the next government to look at the workforce, funding and public health together'.

\section{Prevention not treatment for kids' teeth}

The British Dental Association (BDA) has welcomed a focus on prevention and reduced intervention in a new study on the effectiveness of fillings in children. ${ }^{1}$

However, the Association has stressed that all treatment options must remain available so that dentists can use their expertise and clinical judgement to recommend the most appropriate option for each patient and each tooth.

The three-year UK-wide FiCTION study from academics based in Dundee, Newcastle, Sheffield, Cardiff, Queen Mary University of London, and Leeds tracked children who experienced tooth decay and pain and allocated them to groups receiving conventional treatment (filling plus prevention), sealing in of the decay plus prevention, or prevention alone. The results showed little difference in outcomes between the groups.

The paper recommends that preventive measures can be used to stop decay from worsening in children. But the BDA says the conversation should really be about how to prevent children having tooth decay in the first place, not about how best to treat it when it happens.

The BDA has called on all parties to resource a national programme to prevent child tooth decay, based on existing efforts in both Wales and Scotland. It has long advocated the Scottish programme Childsmile as a potential model for England, a national effort in nurseries and schools with both universal and targeted components that has already reduced the bill for dental treatment costs by $£ 5$ million a year.

England lacks a properly funded equivalent, with local authorities paring back efforts in the face of $£ 85$ million of cuts to public health

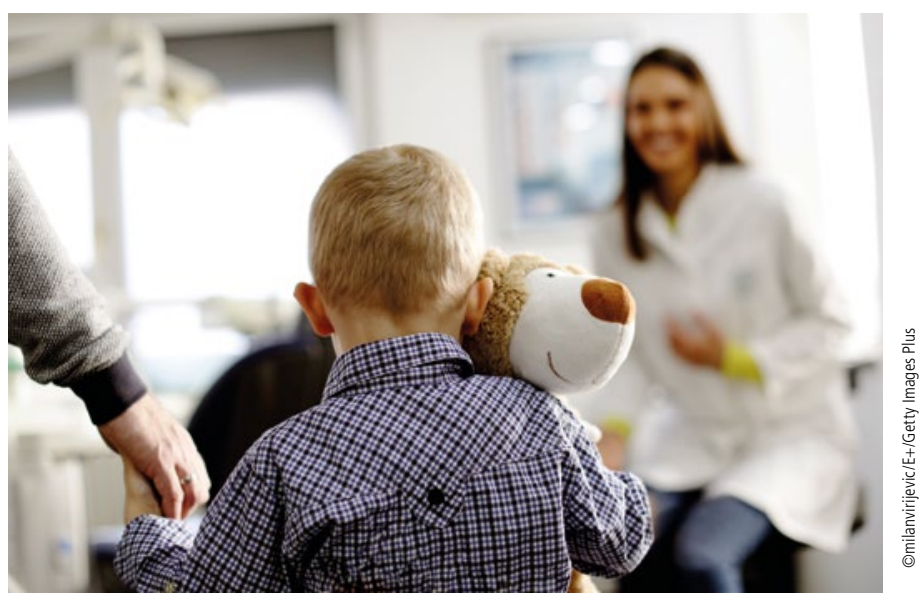

grants. Studies by the King's Fund have found the single biggest areas for cuts have been miscellaneous services, including dental public health.

Tried and tested policies like supervised brushing in early years settings can generate up to a $£ 3.66$ return on investment for every $£ 1$ spent in the most deprived communities, according to Public Health England modelling.

\section{Reference}

1. Innes N P, Clarkson J E, Douglas G V A et al. Child caries management: a randomized controlled trial in dental practice. J Dent Res 2019; doi: 10.1177/0022034519888882 [Epub ahead of print]. 